\title{
Characterization of the Structure of Saudi Crude Asphaltenes by X-ray Diffraction
}

\author{
J ohn W. Shirokoff, ${ }^{\dagger}$ Mohammad N. Siddiqui, and Mohammad F. Ali* \\ The Research Institute and Department of Chemistry, King Fahd University of Petroleum and \\ Minerals, Dhahran 31261, Saudi Arabia
}

Received February 14, 1996. Revised Manuscript Received December 23, $1996^{\otimes}$

\begin{abstract}
Structural characterization studies have been carried out on four commercial Saudi Arabian crude oils. The aromaticity and crystallite parameters of the asphaltenes were studied by X-ray diffraction methods and compared to the average structural parameters cal culated from nuclear magnetic resonance spectra.
\end{abstract}

\section{Introduction}

The long-term future outlook for the hydrocarbon conversion industry is to utilize the heavier and more carbonaceous feedstocks. Such feedstocks are characteristically more difficult to process because they contain substantial amounts of asphaltenes. Asphaltenes are defined as materials insoluble in aliphatic hydrocarbon solvents (n-pentane and n-heptane). In general, asphaltenes have higher aromaticity, heteroatom contents, metal contents, and molecular weights as compared to lighter petroleum fractions and are thereby commonly presumed to represent the most refractory and difficult portion of the feedstocks to process. The molecular species that constitute asphaltenes have been a subject of active research over the past 30 years. These investigations have brought to light some significant facts about asphaltene structure. There is a general consensus of the majority of the researchers that asphal tene contains condensed aromatic systems carrying alkyl, cycloalkyl, and heteroatom constituents. ${ }^{1-3}$

The structural characteristics of asphaltenes are important to refiners for determining the yields from the residual fraction of crude oils and the operating parameters of the process units for deep conversion processes. Two established techniques for determining structural characteristics are X-ray diffraction and nuclear magnetic resonance (NMR). In this paper, we report the structural characterization of four Saudi Arabian crude-oil-derived asphaltenes by X-ray diffraction and we discuss the data in combination with previous NMR results on the same asphaltenes. ${ }^{4}$ In an attempt to explain the relatively higher aromaticity of Arab Berri asphaltenes, high-pressure gel permeation chromatography (HP-GPC) is used to characterize Arab asphaltenes in terms of their molecular size distribution in solution.

\footnotetext{
* To whom correspondence should be addressed.

† The Research Institute, KFUPM, Dhahran.

${ }^{\otimes}$ Abstract published in Advance ACS Abstracts, March 1, 1997.

(1) Speight, J. G. The Chemistry and Technology of Petroleum; Marcel Dekker Inc: New York, 1991.

(2) Mushrush, G. W.; Speight, J . G. Petrol eum products: Instability and Incompatibility; Taylor and Francis: Washington, DC, 1995.

(3) Speight, J. G.; Long, R. B. Fue Sci. Technol. Int. 1996, 14 (1 \& 2), 1-12.

(4) Hasan, M.; Ali, M. F.; Bukhari, A. Fuel 1983, 62, 518.
}

The crude oils produced by the Saudi Arabian Oil Co. (Saudi Aramco) are marketed under the following names:

Arabian Extra Light, which comes from the Berri, Saudi Arabia, field and is produced from the upper J urassic age Arab zone reservoirs, generally ool itic and dol omitic limestones. It is a relatively high API gravity $\left(38.50^{\circ} \mathrm{API}\right)$ and low-sulfur, paraffinic-type crude oil.

Arabian Light is produced from the Ghawar field, which is the largest onshore oil field in the world, and it is also derived from the upper J urassic age Arab zone reservoirs. Arabian Light is a moderately high-gravity $\left(33.80{ }^{\circ} \mathrm{API}\right)$, medium-sulfur, and medium-paraffinic crude oil.

Arabian Medium is produced from the J urassic age Arab zone reservoirs as a multistage separated oil from a blend of the following fields: $65 \%$ Khursaniya, $25 \%$ Qatif, and $10 \%$ Abu-Safah. This crude oil is a mediumgravity $\left(30.40^{\circ} \mathrm{API}\right.$ ) paraffinic wax-containing crude oil.

Arabian Heavy is a relatively low-gravity (28.03 $\left.{ }^{\circ} \mathrm{API}\right)$, high-sulfur, paraffinic wax-containing crude oil. It comprises crude oil from an offshore field, Safaniya, located about 125 mi northwest of the exporting terminal Ras Tanura and is known to be the world's largest offshore oil field. Safaniya oil is produced from the lower Cretaceous age Arab zone reservoirs.

All crude oil leaving the Saudi Aramco production fields, with the exception of those at Safaniya, Marjan, and Zuluf, are sour and contain toxic hydrogen sulfide. Sour crude is sweetened, stabilized, and pumped to the storage facilities before shipment. All crude oil samples studied in this work are stabilized crude from the storage facilities in Ras Tanura.

\section{Experimental Section}

The residue was prepared by removing distillates boiling up to $370{ }^{\circ} \mathrm{C}$ using a Podbielniak column for atmosphericpressure and vacuum distillation using ASTM method D $2892 .{ }^{5}$

I solation of Asphaltenes. Asphaltenes were isolated from the $370{ }^{\circ} \mathrm{C}$ residue by digesting $45 \mathrm{~g}$ of residue with $1350 \mathrm{~mL}$ (30-fold volume) of normal pentane solvent. The mixture was stirred for $90 \mathrm{~min}$ at $1500 \mathrm{rpm}$ and then allowed to stand for $16 \mathrm{~h}$ at room temperature. It was then transferred into 100

(5) Annual Book of ASTM Standards; American Society for Testing and Materials: Philadelphia, PA, 1995; Standard No. D 2892, Vol. 05.02 .

(C) 1997 American Chemical Society 
$\mathrm{mL}$ centrifuge tubes and centrifuged for $60 \mathrm{~min}$ at $1600 \mathrm{rpm}$. The supernatant liquids (maltenes) were decanted, and the mixture was recentrifuged with fresh volumes of normal pentane to wash the asphaltenes. Asphaltenes were collected from the bottom of the centrifuge tubes and then purified by extraction for $24 \mathrm{~h}$ with normal pentane on a Soxhlet extractor at ambient temperature, followed by drying in a vacuum oven at $50{ }^{\circ} \mathrm{C}$ and $2.5 \mathrm{kPa}$ pressure.

Elemental analyses. Elemental analyses of all four asphaltene samples were performed on a Carlo Erba 1106 elemental analyzer.

HP-GPC analyses. The HP-GPC procedure utilized a Waters HPLC system 840, with a Model 501 pump, 712 WISP auto injector, R-401 differential refractometer detector, and a Millennium 2010 chromatography manager for recording chromatograms and accumulating data. The column bank consisted of four Millipore Ultrastyragel columns in series: $10000,1000,500$, and $100 \AA$. The mobile phase was HPLCgrade tetrahydrofuran (THF) at a flow rate of $1.00 \mathrm{~mL} / \mathrm{min}$. About $100 \mathrm{mg}$ of an asphaltene sample was dissolved in 10 $\mathrm{mL}$ of THF at room temperature, then filtered through a 0.2 $\mathrm{mm}$ membrane and an exact volume $(100 \mu \mathrm{L})$ was injected into the HP-GPC system. The GPC profiles and molecular weights were cal culated using the Millennium 2010 computer program.

X-ray Diffraction. X-ray diffraction measurements were made on finely ground powders (about 50-200 $\mu \mathrm{m}$ which were ground by mortar and pestle and checked on a JEOL 840 scanning electron microscope, SEM) of asphaltene with a Philips PW1700 automated diffractometer. In this ground powdered form, many grains come into orientation and the quality of the diffraction pattern is greatly improved. The instrument has a vertical goniometer attached to a broad-focus X-ray tube with a copper target operating at $40 \mathrm{kV}$ and 40 $\mathrm{mA}$ and a graphite monochromator. An autodivergent slit, 0.1 $\mathrm{mm}$ receiving slit, scan rate $0.01^{\circ} 2 \theta \mathrm{s}^{-1}$ and count time of 5 $\mathrm{s} / \mathrm{step}$ were employed. The analysis is computer assisted so that the interplanar spacing values can be corrected for the instrument error function by analyzing a silicon standard. The computer was also used to perform peak profile analysis. The profile fitting was used to accurately determine peak positions, widths (full width at half-maximum, fwhm), backgrounds, intensities, and net peak areas calculated. The technique involves specifying a mathematical model to represent the expected profile shape. ${ }^{6}$ The profile fitting uses a model that employs 12 intrinsic parameters to describe the profile, the instrument aberrations, and wavelength-dependent contributions to the profile. These contributions are systematic with $2 \theta$. They are determined with an initial estimate of the $\mathrm{K} \alpha 1$ peak position and intensity. The model also utilizes three parameters to describe the sample-dependent parameters: angle position, intensity, and line broadening. These are fitted to the experimental diffraction profile using a Marquardt nonlinear least-squares algorithm. ${ }^{7}$ The profile fitting stops when convergence has been reached. Convergence is reached when the difference in the $\chi$-squared value between two iterations became equal to or less than 0.3. In the case of measuring the net peak areas of the $\gamma$ and graphene peaks, the areas of the peak profile are measured at reduced intensity (background subtracted) over the range required $\left(11-33^{\circ} 2 \theta\right)$ as described by the authors. 8,9

(6) PC-APD Version 3.6, Software for Automated Powder Diffraction - Operation Manual, Fifth Edition, Philips Analytical X-Ray, Eindhoven, The Netherlands, February 1994, pp 611-615.

(7) Schreiner, W. N.; J enkins, R. Profile fitting for Quantitative Analysis in X-Ray Powder Diffraction. Adv. X-Ray Anal. 1983, 26, 141.

(8) Schwager, I.; Farmanlan, P. A.; K wan, J . T.; Weinberg, V. A.; Yen, T. F. Anal. Chem. 1983, 55, 42.

(9) Yen, T. F. Multiple Structural Orders of Asphaltenes. In Asphaltenes and Asphalts, 1. Developments in Petroleum Sciences; Yen, T. F., Chilingarian, G. V., Eds.; Elsevier Sci. Publ.: New York, 1994; Vol 40, Chapter 5, p 111 and references therein.
Table 1. Aromaticity and Crystallite Parameters of Four Saudi Crude Asphaltenes

\begin{tabular}{ccccc}
\hline \multirow{2}{*}{$\begin{array}{c}\text { aromaticity and } \\
\text { crystallite } \\
\text { parameters }\end{array}$} & $\begin{array}{c}\text { Arab } \\
\text { Heavy }\end{array}$ & $\begin{array}{c}\text { Arab } \\
\text { Medium }\end{array}$ & $\begin{array}{c}\text { Arab } \\
\text { Light }\end{array}$ & $\begin{array}{c}\text { Arab } \\
\text { Berri }\end{array}$ \\
\hline $\mathrm{f}_{\mathrm{a}}$ & 0.19 & 0.16 & 0.19 & 0.20 \\
$\mathrm{~d}_{\mathrm{m}}, \AA$ & 3.6 & 3.6 & 3.6 & 3.6 \\
$\mathrm{~d}_{\gamma}, \AA$ & 4.4 & 4.5 & 4.4 & 4.4 \\
$\mathrm{~L}_{\mathrm{a}}, \AA$ & 12.3 & 11.9 & 13.0 & 13.0 \\
$\mathrm{~L}_{c}, \AA$ & 24.7 & 23.2 & 24.0 & 22.7 \\
$\mathrm{M}$ & 8.0 & 7.5 & 7.8 & 7.4
\end{tabular}

The method of obtaining the aromaticity and crystallite parameters is found elsewhere, ${ }^{10,11}$ and is summarized as follows:

A comparative estimate of the aromaticity $f_{a}$ was determined by calculating the areas $A$ of the resolved peaks for the $\gamma$ and graphene bands using the following formula:

$$
\mathrm{f}_{\mathrm{a}}=\mathrm{C}_{\mathrm{A}} / \mathrm{C}=\mathrm{C}_{\mathrm{A}} /\left(\mathrm{C}_{\mathrm{A}}+\mathrm{C}_{\mathrm{S}}\right)=\mathrm{A}_{(\text {graphene) }} /\left(\mathrm{A}_{(\text {graphene) }}+\mathrm{A}_{(\gamma)}\right)
$$

where $C_{S}, C_{A}$, and $C$ are the number of saturated, aromatic, and total carbon atoms per structural unit.

The layer distance between aromatic sheets was calculated from the maximum of the graphene band by the Bragg relation:

$$
\mathrm{d}_{\mathrm{m}}=\lambda /(2 \sin \theta)
$$

where $\lambda$ is the wavelength of the $\mathrm{Cu} \mathrm{K} \alpha$ radiation and $\theta$ is the Bragg angle.

The distance between the saturated portions of the molecules or interchain layer distance is given by this relationship:

$$
\mathrm{d}_{\gamma}=5 \lambda /(8 \sin \theta)
$$

The average diameter of the aromatic sheets on the basis of the Scherrer crystallite size formula is as follows:

$$
\mathrm{L}_{\mathrm{a}}=1.84 \lambda /(\omega \cos \theta)=0.92 / \mathrm{B}_{1 / 2}
$$

where $B_{1 / 2}$ is the full width at half-maximum using the (11) band and $\omega$ is the bandwidth.

The average height of the stack of aromatic sheets perpendicular to the plane of the sheet was calculated from the full width of the graphene band at half-maximum using the equation

$$
\mathrm{L}_{\mathrm{c}}=0.9 \omega \cos \theta=0.45 / \mathrm{B}_{1 / 2}
$$

The number of aromatic sheets in a stacked cluster, $M$, was calculated from the values of $L_{c}$ and $d_{m}$ as follows:

$$
M=\left(L_{d} / d_{m}\right)+1
$$

\section{Results and Discussion}

The results obtained by calculating all of the parameters from X-ray measurements of the four Saudi crude asphaltenes are summarized in Table 1 . The doublet of the $\gamma$ and graphene layer stacking peaks at about $20^{\circ}$ and $25^{\circ}=2 \theta$ has been determined for each sample and their peak profiles were fitted.

The results indicate that the average layer distance between aromatic sheets $\left(d_{m}\right)$ measures about $3.6 \AA$, the average interchain layer distance $\left(\mathrm{d}_{\gamma}\right)$ is between 4.4 and

(10) Yen, T. F., Erdman, J . G.; Pollack, S. Anal. Chem. 1961, 33, 1587.

(11) Wen, C. S.; Chilingarian, G. V.; Yen, T. F. Properties and Structure of Bitumens. In Bitumens, Asphalts and Tar Sands; Chilingarian, G. V., Yen, T. F., Eds.; Developments in Petroleum Science 7; Elsevier Sci. Publ.: Amsterdam, 1978; Chapter 7, 155. 


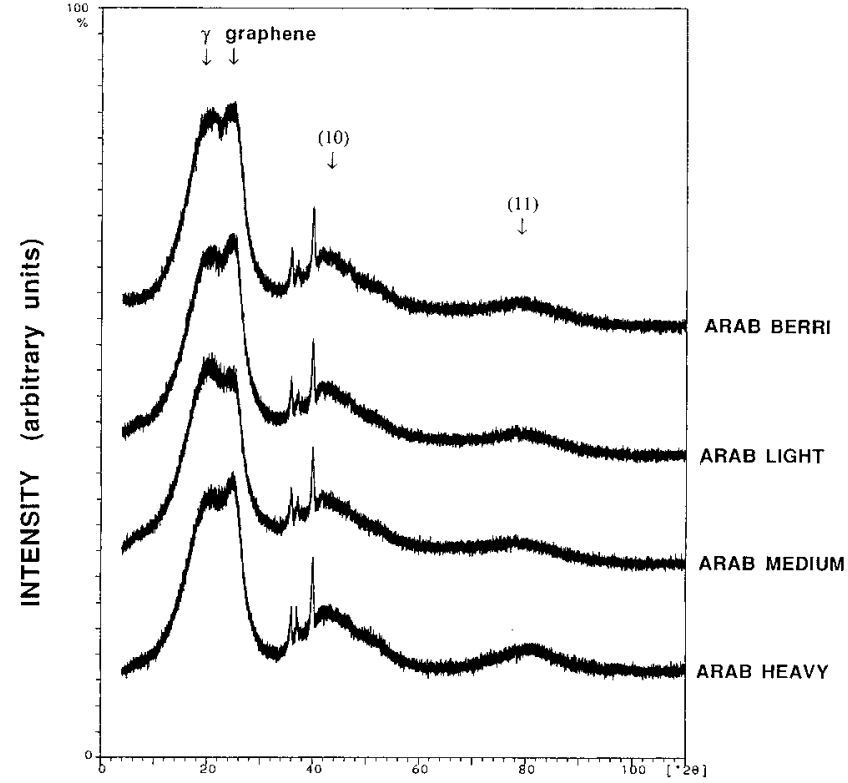

$2 \theta$

Figure 1. X-ray diffraction pattern of four Saudi crude asphaltenes.

$4.5 \AA$, and the average stack height of the aromatic sheets perpendicular to the plane of the sheets $\left(L_{c}\right)$ ranges between 22.7 and $24.7 \AA$. The number of aromatic sheets in a stacked cluster $(\mathrm{M})$ is between 7.4 and 8.0. The average diameter of the aromatic sheets $\left(L_{a}\right)$ is between 11.9 and $13.0 \AA$. The layer distance $\left(d_{m}\right)$ between aromatic sheets (graphene planes) is found to be more or less constant. The distance between saturated portions of the molecules $\left(\mathrm{d}_{\gamma}\right)$ is higher for Arab Medium asphaltene and marginally higher for Arab Light asphaltene when compared to Arab Heavy and Arab Berri asphaltenes.

The X-ray patterns for the four Saudi crude asphaltenes appear in Figure 1, vertically offset from each other by 1250 counts and showing $31 \%$ of the vertical scale when plotted. These four patterns are in general very similar, and each contains the $\gamma$ peak, graphene layer stacking peak, the (10) peak, and the (11) peak. As a consequence of their similarity, the measurements for the graphene and (11) peaks full width at halfmaximum (fwhm) do not change much. Therefore the calculations for the average diameter of the aromatic sheets $\left(L_{a}\right)$ and the average height of the stack of the aromatic sheets $\left(L_{c}\right)$ show little deviation. The small difference in the data that does exist indicates somewhat higher $L_{a}$ values for the Arab Light and Arab Berri asphal tenes.

Figure 2 shows the resolution of the peak profiles of the $\gamma$ peak and graphene layer stacking peak over the range $11-33^{\circ} 2 \theta$ for the four Saudi crude asphaltenes. As evidenced by a small amount of residue left at the zeroline after background subtraction, the peak profiles appear to be well resolved. From these data, the Arab Berri asphaltene is found to possess the highest estimate of aromaticity $\left(\mathrm{f}_{\mathrm{a}}\right)$ followed by Arab Light and Arab Heavy, whereas Arab Medium was the lowest. These results are somewhat consistent with the previous findings for the same asphaltenes studied by NMR, with the exception of the result of Arab Medium. ${ }^{12}$ However, the XRD-pattern in Figure 1 and the peak profile in Figure 2 for Arab Medium shows a lower graphene

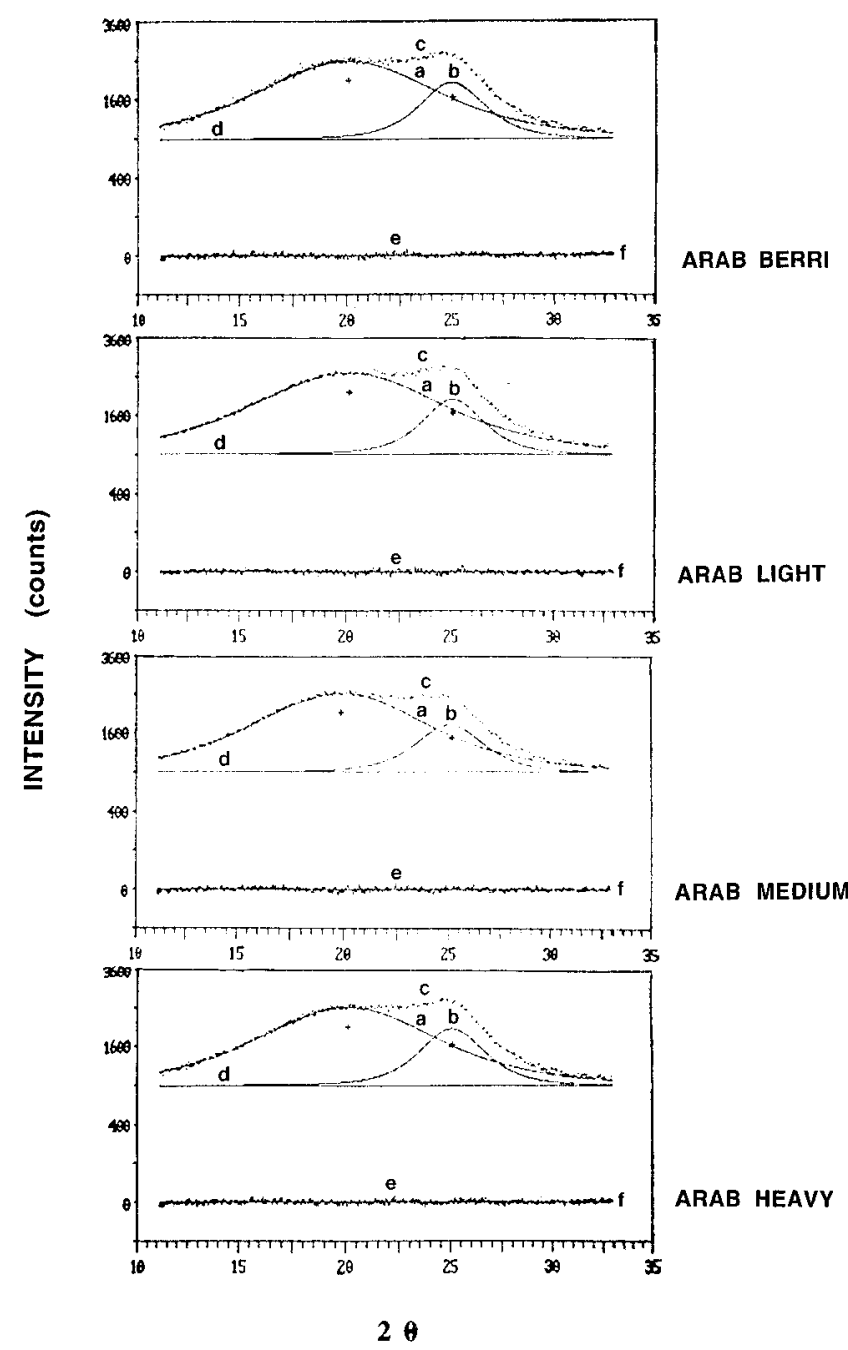

Figure 2. X-ray diffractograms of four Saudi crude asphaltenes showing the peak profile fit as (a) $\gamma$ peak, (b) the graphene layer stacking peak in the $2 \theta$ range $11-33^{\circ}$, (c) raw data points, (d) the background, (e) the residue which is the raw data minus the sum of the profiles, and ( $f$ ) the zero line. This figure is reproduced from photographs taken off the XRD systems computer screen.

Table 2. Elemental Analyses of Four Saudi Crude Asphaltenes

\begin{tabular}{crrrr}
\hline & \multicolumn{4}{c}{ asphaltene, wt \% } \\
\cline { 2 - 5 } elements & $\begin{array}{c}\text { Arab } \\
\text { and ratios }\end{array}$ & $\begin{array}{c}\text { Arab } \\
\text { Heavy }\end{array}$ & $\begin{array}{c}\text { Arab } \\
\text { Light }\end{array}$ & $\begin{array}{r}\text { Arab } \\
\text { Berri }\end{array}$ \\
\hline C & 83.17 & 83.65 & 84.23 & 85.05 \\
$\mathrm{H}$ & 8.28 & 8.31 & 7.76 & 7.24 \\
$\mathrm{~N}$ & 0.84 & 0.65 & 0.75 & 0.27 \\
$\mathrm{~S}$ & 7.18 & 6.41 & 6.30 & 6.30 \\
$\mathrm{O}^{\mathrm{a}}$ & 0.53 & 0.98 & 0.96 & 1.12 \\
$\mathrm{H} / \mathrm{C}$ & 1.19 & 1.18 & 1.10 & 1.02
\end{tabular}

a By difference.

stacking peak intensity and a smaller graphene peak profile area, the latter of which is used in calculating $\mathrm{f}_{\mathrm{a}}$, when compared to other asphaltenes. The elemental analyses of these asphaltenes are given in Table 2 and indicate that sulfur contents decrease from Arab Heavy (7.18) to Arab Berri (6.30) asphaltenes. However, the oxygen contents increase from Arab Heavy (0.53) to Arab Berri (1.12) asphal tenes. The $\mathrm{H} / \mathrm{C}$ ratios of these asphal tenes gradually decrease from Arab Heavy (1.19)

(12) Hasan, M.; Siddiqui, M. N.; Arab, M. Oil Gas J . 1988, Feb. 8 Technology, 38. 
Table 3. NMR Parameters of Four Saudi Crude Asphaltenes

\begin{tabular}{lcccc}
\hline & \multicolumn{4}{c}{ asphaltene } \\
\cline { 2 - 5 } \multicolumn{1}{c}{ parameters } & $\begin{array}{c}\text { Arab } \\
\text { Heavy }\end{array}$ & $\begin{array}{c}\text { Arab } \\
\text { Medium }\end{array}$ & $\begin{array}{c}\text { Arab } \\
\text { Light }\end{array}$ & $\begin{array}{c}\text { Arab } \\
\text { Berri }\end{array}$ \\
\hline $\mathrm{H}_{\mathrm{ar}}$ & 5.3 & 11.2 & 14.2 & 15.4 \\
$\mathrm{C}_{\mathrm{sat}}$ & 45.3 & 39.3 & 35.6 & 25.4 \\
$\mathrm{C}_{\text {ar }}$ & 54.7 & 60.7 & 64.4 & 74.6 \\
\% straight chain & 19.2 & 21.0 & 13.6 & 13.1 \\
av chain length & 19.2 & 20.0 & 13.6 & 16.3 \\
$\mathrm{f}_{\mathrm{a}}$ & 0.55 & 0.60 & 0.64 & 0.74 \\
$\mathrm{f}_{\mathrm{c}}$ & 0.65 & 0.65 & 0.64 & 0.60
\end{tabular}

to Arab Berri (1.02) asphaltenes. A high $\mathrm{H} / \mathrm{C}$ ratio indicates the presence of long al iphatic straight-chain compounds, whereas a low $\mathrm{H} / \mathrm{C}$ ratio is a good indication of the presence of polynuclear aromatic systems. The $\mathrm{H} / \mathrm{C}$ ratios suggest that the Arab Berri asphaltenes contain more-condensed polynuclear aromatic rings, whereas Arab Heavy asphaltenes possess a lesscondensed aromatic system with longer paraffinic chains in their structure. The specific gravity and sulfur contents of these four crude oils are also reported to decrease from Arab Heavy to Arab Berri in the same order. ${ }^{4}$ In fact, the Arab Berri crude oil is classified as Arab Extra Light.

The average structural parameters of all four asphal tenes have been calculated in a previous study from their proton and carbon NMR spectra. The results are reproduced in Table 3.12 Arab Berri asphaltenes are found to possess the highest aromatic hydrogen content (15.4\%) followed by Arab Light (14.2\%), Arab Medium (11.2\%), and Arab Heavy (5.3\%). The relative depletion of aromatic protons in the Arab Heavy asphaltene suggests that in this asphaltene the aromatic structures are highly condensed and are more substituted than the other studied asphaltenes. The saturated carbon content is found to be highest in Arab Heavy (45.4\%), followed by Arab Medium (39.3\%), Arab Light (35.6\%), and Arab Berri (25.4\%). The percent distribution of straight-chain alkanes is highest in Arab Medium (21.0\%) and lowest in Arab Berri (13.1\%), whereas Arab Heavy (19.2\%) and Arab Light (13.6\%) show intermediate values. The Arab Medium asphaltenes have the longest average chain length followed by Arab Heavy asphaltenes. The shortest chain length is found in Arab Light asphaltenes. The aromatic carbon content is highest in Arab Berri (74.6\%) and lowest in Arab Heavy asphaltenes (54.7\%). The Arab Medium and Arab Light show intermediate values. The aromaticity factor, $\mathrm{f}_{\mathrm{a}}$, which is the ratio of aromatic carbons to the total number of both aliphatic and aromatic carbons, is highest in Arab Berri asphaltenes (0.74) and lowest in Arab Heavy (0.55) asphaltenes. The ratio of bridgehead carbons to total aromatic carbons, $f_{c}$ indicates the extent of compactness and ring condensation in asphaltenes. This parameter decreases from Arab Heavy (0.65) to Arab Berri (0.60). Thus, the Arab Heavy asphaltenes possess the highest percentage of bridgehead carbons in their skeleton.

The HP-GPC profiles (Figure 3 ) of the four Saudi crude asphaltenes show that the profile for Berri asphaltene is significantly different from the other three crude asphaltenes. The peak results (Table 4) also show a decrease in the large molecular size (LMS) material and an increase in medium molecular size (MMS) and small molecular size (SMS) materials for Berri asphalt-

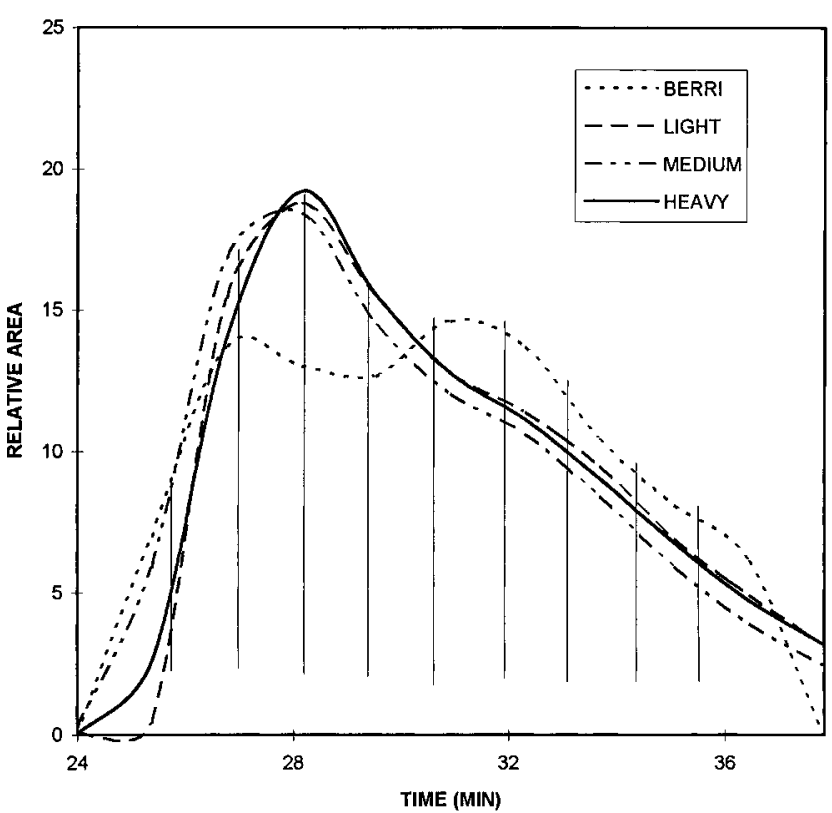

Figure 3. HP-GPC profile of four Saudi crude asphaltenes.

Table 4. Peak Results for HP-GPC Profiles for Four Arab Asphaltenes

\begin{tabular}{ccc}
\hline asphaltenes & $\begin{array}{c}\text { retention } \\
\text { time }(\min )\end{array}$ & \% area \\
\hline Arab Berri & 28.100 & 30.56 \\
& 32.183 & 42.82 \\
Arab Light & 35.967 & 13.60 \\
& 43.350 & 13.01 \\
Arab Medium & 27.650 & 79.26 \\
& 35.967 & 8.09 \\
Arab Heavy & 42.533 & 3.84 \\
& 51.317 & 8.81 \\
& 27.167 & 90.22 \\
& 35.967 & 6.81 \\
& 42.883 & 2.97 \\
& 27.483 & 87.64 \\
& 35.983 & 8.28 \\
& 40.717 & 0.01 \\
& 43.033 & 4.07
\end{tabular}

enes. LMS materials are known to be made up of condensed polynuclear aromatic systems bearing small naphthenic and alkyl systems on their periphery. ${ }^{1}$ The evolution of a crude oil involves a process of continuous, irreversible change, usually called "maturation", which leads from a heavy, N/S/O-rich "immature" crude oil toward "mature" crudes which are lighter. Temperature has a major role in maturation, and thermal cracking is the most important mechanism. ${ }^{13}$ The sequence of compositions during thermal maturation of crude oil shows the parallel development of increasingly aromatic heavy molecules and progressively smaller paraffins. ${ }^{14}$ The four crude oils examined here appear to be following a similar trend in that the oil from the less mature Cretaceous age zone (Arab Heavy) is relatively heavier and lower in aromatic carbon content than the oils from the upper J urassic age zone (Arab Berri). The HP-GPC profiles al so support the findings from $X$-ray diffraction and NMR studies for the higher aromaticity in Arab Berri asphaltenes.

(13) Barker, C. Organic Geochemistry in Petroleum Exploration AAPG Book Store: Tulsa, OK, 1986.

(14) Connar, J.; LeTran, K; Van der Weeide, B. Alterations of Petroleum in Reservoir; Proceedings 9th World Petroleum Congress, 1975; Volume 2, pp 171-178. 


\section{Conclusions}

X-ray diffraction studies of the four Saudi crude asphaltenes support the general concept of condensed aromatic sheets (having a tendency to stack) bearing naphthenic and alkyl systems on their periphery as the structure of asphaltenes. A comparative estimate of the aromaticity $\left(\mathrm{f}_{\mathrm{a}}\right)$ indicates that it decreases with increasing API gravity for the four Arab crude asphaltenes. HP-
GPC profiles of the asphaltenes are also consistent with findings for the same asphal tenes studied by NMR and $\mathrm{X}$-ray diffraction.

Acknowledgment. The authors would like to thank the Chemistry Department and Research Institute of King Fahd University of Petroleum and Minerals for supporting this research.

EF 960025C 